Meta

Journal des traducteurs

Translators' Journal

\title{
Translation as a Transaction Cost
}

\section{Anthony Pym}

Volume 40, numéro 4, décembre 1995

URI : https://id.erudit.org/iderudit/003880ar

DOI : https://doi.org/10.7202/003880ar

Aller au sommaire du numéro

Éditeur(s)

Les Presses de l'Université de Montréal

ISSN

0026-0452 (imprimé)

1492-1421 (numérique)

Découvrir la revue

Citer cet article

Pym, A. (1995). Translation as a Transaction Cost. Meta, 40(4), 594-605.

https://doi.org/10.7202/003880ar

\section{Résumé de l'article}

L'auteur esquisse un modèle traductologique qui considère les actants sources et cibles comme des acteurs sociaux engagés dans une communication afin d'en retirer chacun des avantages. Ce modèle admet, entre autres, l'idée que l'effort social concédé dans la communication ne doit plus dépasser le bénéfice mutuel retiré de cette interaction. Appliqué à la traduction, ce modèle aurait pour but la formulation d'hypothèses générales sur le contexte dans lequel la traduction devrait s'exercer et quels devraient en être les coûts sociaux.
Ce document est protégé par la loi sur le droit d'auteur. L'utilisation des services d’Érudit (y compris la reproduction) est assujettie à sa politique d'utilisation que vous pouvez consulter en ligne.

https://apropos.erudit.org/fr/usagers/politique-dutilisation/ 


\title{
TRANSLATION AS A TRANSACTION COST*
}

ANTHONY PYM

Unoversitat Ronira i Lirgili. Tarragona, Spain

\begin{abstract}
Résumé
L'auteur esquisse un modele tradurtologique qui considere les actants sources et cibles comme des acteurs sociaur engage's dans une communication afin d'en revirer chacun des arantages. Ce modele admet. entre autres, l'idée que l'effort social roncidé dans la communication ne doit pas dépasser le hénéfice mufuel rétiré de celfe interaction. Appliqué a la traduction. ce modele aurait pour hut la formulation d hypothe'se's générales sur le'

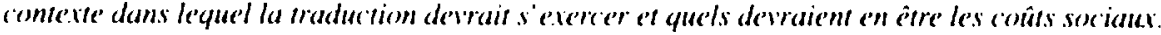

\section{Abstract}

The aushor develops a translation theory which considers source and target elements as sorial acrors engage'd in communication in order to achieve mutual benefits. The model suggests, among other things. that the social effort put into communication should not exceed the mutral benefit onsuing from the interottion. Applied to tronslation, the aim of the model is of formulate general hypothese's about the context in which translation should oceur and the social costs it should inolie.

Translation theory has long suffered a general conflict between source-focused and target-focused approaches, with most theorists giving priority to one side or the other. Some of this conflict might be resolved through an approach that starts from both sides at once, privileging neither source nor target. In view of this ideal, the model to be developed here sees the source and target sides as social actors engaged in communication in order to achieve mutual benefits. The model allows certain hypotheses to be adapted from simple neoclassical negotiation theory, particularly the idea that the social effort put into communication - the transaction costs - should not exceed the mutual benefit to ensue from successful interaction. Translation can be seen as a specific and variable transaction cost that is subject to economic and ethical constraints. The aim of the model is to formulate general hypotheses about the situations in which translation should take place and what social costs it should involve.

The following explanation will seem insultingly reductive to some and perhaps unnecessarily abstruse to others. I can only beg patience from both sides.

And so to the model.

\section{NEG;OTIATION AND MUTUAL, BENEFITS}

The simplest of the cooperation games used in negotiation theory is based on actors investing in common services. Let us say $A$ and $B$ each have $\$ 10$ and can allocate any part of that sum to a common fund through which they will receive a common service. The value of the service is presumed to allow a better outcome than would be the case if the actors invested separately. If $A$ and $B$ live in the same street and want to have rubbish taken away from their homes, they both stand to gain from having just one truck come to their street rather than have two individual trucks come to two individual houses. The actors should negotiate in order to achieve this mutually beneficial outcome. 
Let us now suppose the outcome of cooperation is $33.3 \%$ greater than the outcome of non-cooperation. If each actor invests $\$ .5$ the common fund will be $\$ 13.33$ $(5+5+33.3 \%)$ and the value returned to each could be half that sum, $\$ 6.66$. When this is added to the $\$ .5$ not invested, we find each actor finishes up with $\$ 11.66$ worth of resources plus services. Both have received more value than would be the case had they not cooperated. Benefits exist for both sides. Both actors will continue to invest, a common rubbish collection service will be established, and social life will be a little happier as a result.

This is fine for as long as each actor invests $\$ 5$ and can be sure the other actor is going to invest the same sum. But social life is full of inequalities. Not everyone is able to make the same investment. Not everyone wants to. What happens then?

In some cases. unequal capacities do not really matter. Let us suppose B can only invest \$3. If $A$ still invests $\$ 5$, the common fund is $\$ 10.66(5+3+33.3 \%)$ and the outcome - if we can simplify matters by splitting the benefits $50 / 50$ - is that A will have $\$ 10.33$ and $B$ will have $\$ 12.33$ worth of resources and services. Although the investments and outcomes are unequal, the cooperation is still beneficial for both sides. Actor $A$ has still gained 33 cents. Cooperation will thus still continue. Social life will not only be happier but the process may become compatible with a socially beneficial redistribution of wealth.

Yet social life is also full of self-interest. Some self-interested actors are rational egoists. If $B$ is such an egoist and can be sure $A$ is going to invest $\$ 5$. B can maximize their own henefits by only investing $\$ 3$, regardless of how much they can actually afford to put in. Mutual henefits will still exist; cooperation will still continue. In fact, a rational egoist B need invest only as much as is necessary to ensure that A finishes up slightly ahead and will keep cooperating. Necclassical economists tend to believe this kind of self-interest is ethically legitimate. Actor B has, after all, ensured A's continued existence and economic betterment. A whole branch of mathematics now calculates the minimum thresholds involved. to ensure that economic ethics remain as rationally egoistic as possible.

Some self-interested actors might nevertheless be considered irrational egoists or cheats. If B is sure A is going to invest $\$ 5$, they could decide to put in only $\$ 2$. Under the above conditions the outcome would now be that $A$ finishes up with $\$ 9.66$ and $B$ has \$13.66. Actor B has gained high benefits but A now has less benefits than their starting position. Actor $A$, if free enough to be at all rational, will not continue with the cooperation. They will either hire their own individual rubbish truck or go off and stan negotiating with someone else. B has won the battle but lost the war. Both actors will have to find other partners in future, since this particular cooperation will remain a purely one-off affair. Social life will be less happy as a result. making the outcome ethically unacceptable. We have been looking at the following three games:

\begin{tabular}{|c|c|c|c|c|}
\hline \multicolumn{3}{|c|}{ Investments } & \multicolumn{2}{|c|}{ Outcomes } \\
\hline & A & B & A & B \\
\hline Game 1. & 5 & 5 & 11.66 & 11.66 \\
\hline Game 2. & 5 & 3 & 10.33 & 12.33 \\
\hline Game 3. & 5 & 2 & 9.66 & 13.66 \\
\hline
\end{tabular}

Many further games could be added to this table, especially since the common cake can be split in any number of ways (in proportion to the amounts invested, asymmetric opportunity costs, different risk calculations, etc.). But an extended list of variants would not alter our main point. Since we are interested in the ethical requirement that each actor ensure at least the long-term well-being of the other - rather than ensure Mosaic tit- 
for-tat or nationalist zero-sums - our purposes are sufficiently served by the threshold between games 2 and 3, between successful and unsuccessful cooperation. In cases where $B$ is sure A will invest a certain amount, this threshold can be calculated faurly exactly (under the above conditions, if A invests $\$ 5$ a rational egoist B should invest just over $\$ 2.50$ ). However, the beauty of neoclassical ethics is that both $A$ and $B$ can be rational egoists. Both can modify the amounts they invest. So neither can be really sure how much the other is going to put in. Social life is full of uncertainty and mistrust. Each actor must now try to predict the other's future actions. This is where rational cooperation becomes interesting; the $\$ 10$ game becomes a series of prisoner's dilemmas: calculations have to be based on the probability of the other actor's investments. More important, in order to attain cooperation, each actor needs information upon which their probabilistic calculations can be based. The location and use of this information, necessary for relations of relative mutual trust and prediction, incurs significant costs that must be incorporated into the overall calculation. as we shall now see.

\section{TRANSACTION COSTS}

The idea of cooperation leading to mutual benefits is not limited to rubbish disposal. It can be applied to any form of social contract. from the simple exchange of goods to the development of taxation and state institutions. It is also the basis of international negotiations. If free trade is considered to be of potential mutual benefit, one might try to negotiate GATT or NAFTA accords. Nuclear disarmament might also be of mutual benefit, justifying extensive negotiation in order to achieve cooperation. On all these levels, each actor must try to predict other actors' current status and future actions. A restaurant proprietor might look at how a client is dressed in order to predict if the bill is going to be paid: the client looks at the restaurant to see if it warrants the advertised prices. Similarly, the United States and the Soviet Union once looked at each other's nuclear arsenals in order to calculate thresholds for rational disarmament. But the bankrupt client in a restaurant can dress well in order to deceive: insubstantial food can be served in fancy plates: and nuclear arsenals were calculated in many cunningly different ways. Prediction of the other's status and future actions has never been an easy affair.

The information needed for probabilistic prediction can come from many sources. One might look at the way the other actor has behaved in the past (a job candidate presents a curriculum vitae); one could carry out research into the other's financial status, cultural background and psychological make-up: one might engage in long haggling processes to find out just how much the other actor is really prepared to concede. Any information could prove valuable.

Yet the collection and evaluation of information is an expensive business. One has to invest not just in the projected mutual benefits but also in the necessary informationgathering process, including arrangement of the contact situation. These latter investments in the gathering and use of information are called transaction costs.

The transaction costs in the above games have artificially been fixed at zero. If we now suppose each actor has to invest 50 cents in order 10 organize the cooperation and attain a position of relative trust, we find that game 2 , where $A$ was only 33 cents ahead. has become unsuccessful. At zero transaction cost, actor $A$ could benefit from this game; at a 50-cent transaction cost $A$ finishes up making a loss. The game will not lead to any stable social relationship. It follows that, for each actor, the transaction costs should be less than the projected benefit.

If we insist that each side should ethically ensure the well-being of the other, the transaction costs that most interest us are not directly those borne by individual actors or 
their agents (possibly translators). We are more concerned with the total transaction cost born by all actors together. Like mutual benefits, the cost-cake can be cut in any number of ways, but its total sum will still represent the bilateral social effort put into the transaction. If cooperation ethics are to be observed, the total transaction costs clearly should not be more than the total mutual benefits.

This analysis can be taken further. There will obviously be a level of total transaction cost at which no interaction can be mutually beneficial ( $\$ 3.33$ in the above example). More generally, the higher the social effort, the more restricted the number of games with mutually beneficial outcomes. Transaction costs should thus be kept not only below the upper threshold but also low enough to allow for a range of possible successful games corresponding to the probabilistic calculations of both actors. Absolute certainty may be ideal but it is mostly $t(x)$ expensive to altain. Effort must be kept within a range of relative certainty proportional to the benetits of the cooperation concerned. Of course, there will almost always be some uncertainty. Most decisions have to be based on incomplete calculations, hunches, intuition, the following of one's heart or a feeling in the gonads. These are all ways of acting with limited transaction costs.

Should transaction costs then be best fixed as close to zero as possible? There will be a tendency towards decreasing costs if two actors keep cooperating successfully. Whatever the initial transaction costs, they will gradually build up an affective relationship of trust and mutual prediction that can be maintained with little further information input. But this kind of assurance is more difficult to attain in multilateral situations. If transaction costs are so low that all information is uniformly available to everyone, each actor can negotiate with every other actor, shopping around to fix their investments at the lowest possible thresholds. Cooperative arrangements will tend to be purely rationalist one-off affairs, better conducted by computers than people. Indeed, according to Keohane "in certain situations an infinite series of available coalitions may form" (1984: 87). Such situations would not give relationships of mutual trust and prediction a chance to develop. neither rationally nor affectively. Social life will be less happy as a result.

Some transaction cosls should thus be maintained and structured in such a way that the number of actors is restricted. The conventions of friendship do this, as indeed do most international organizations. NATO is an institution for the exchange of strategic information and promises between its members. It does little more than structure transaction costs between a limited number of actors. Indeed. NATO's use of transaction costs is so beneficial to its members that the organization continues to exist in the absence of the purpose for which it was originally set up, and now does so by carefully restricting the entry of new members. Indeed, if cooperation is the aim. any restrictive organization is better than none at all.

This idea can of course be applied to individual tongues and cultures, which structure information and transaction costs so as to enable cooperation between the participating members, regardless of the initial purposes that gave rise to the structures concerned. One might also see state bureaucracies as apparatuses for the structuring of transaction costs within a society. The idea has numerous applications on many social levels.

But it is time we put translation into this framework.

\section{TRANSLATION AS A TRANSACTION COST}

Transaction costs can include the production, location, transfer, translation, and evaluation of information. Although translation need not always figure in this chain it can become a key element. There are at least three reasons for this special importance. First, translation is used in specifically transcultural communication, in situations where shared 
norms have generally not been as firmly established as is the case in intracultural communication. Second, translation is a relatively high but controllable transaction cost. If kept at expensive levels it can condemn many potentially cooperative relationships to failure. And third, there is a link between translation costs and the costs of evaluating the translator's output. If a machine-produced translation is relatively cheap but difficult to read, the low translation cost is offset by high cost of extracting pertinent information. By modifying translation costs, one can also modify evaluation costs and thus extend or restrict the number of actors able to participate in the cooperation. Each of these points requires further comments.

Whether or not one agrees that the production of a translation by definition marks a border between cultures, communication requiring translation remains particularly problematic. At least since Northrop (1952), negotiation theory has recognized that the existence of different political and linguistic cultures presents special difficulties for any international agreement. Yet this does not mean that all cultural differences are of equal importance. When Rocky or Rambo grunts something idiomatic that the American audience finds difficult to understand - was it English? was it language? --. a pedantic dubber or subtitler into a foreign language could spend hours locating the nuance, analyzing its contextual discursive impact and calculating a target-culture version. But the translator would soon be out of business. The pertinent mutual benefits - money for the film industry, visual action for the audience - require minimal translation costs. The filmmakers and the audience already trust and predict that the other party will supply the goods. In such a situation any grunt will do, although a subtitled one would probably be so obtrusive as to reduce mutual henefits. The translator should move as quickly as possible to more demanding tasks. At the other extreme, however, there are cases where potential mutual benefits are so great and yet so difficult to attain that extremely high translation costs are justified. An Israeli government interested in negotiating with Syria might even employ someone like Gideon Toury - while doing his army service - to translate a biography of President Hafez. Assad into Hebrew, complete with the employment of Arabists to revise the text and to add an introduction. When the stakes are high. the social effort put into translation can also be high.

The particular interest of translation is that it is a relatively controllable transaction cost. Once the desirability of certain information has heen ascertained, the costs of production, Jocation and transfer (all non-translational) are relatively fixed. Their sum can be acceptable at any level from just below the projected henefits to just above zero (remembering that it is beneficial to have some level of transaction some costs). But the only way really to control such variability is by limiting the initial desire to seek the information. The insertion of translation into this chain potentially enables greater control. especially if we understand translation as encompassing a wide range of translational products. Gouadec (1989: 22-30) usefully describes such products as including anything from a bibliographic reference and summary of contents (traduction signaléticule) to a complete representation of as many textual factors as possible (traduction absoluc), the choice of one type or another depending on the communicative purpose of the information. Of particular interest here is what might be termed "pretranslating." understood as use of the lower-cost end of such a scale as a stage prior to any work at the higher-cost end. Pretranslating can allow information flows to be vetted, creating loops to and from decisions to produce fuller translations. Such processes can significantly control transaction costs.

In general, however, translation must be recognized as a relatively high-cost operation. whether measured in terms of social effort. rates of pay. or the conseyuences of error. The use of pretranslations can reduce costs but it cannot do away with the fact that 
translation should only become a transaction cost when significant mutual benefits are projected. Translation is not for any old cross-cultural contact.

As vetting processes or pretranslations demonstrate, translation costs are closely related to variable evaluation costs. A low-cost pretranslation may allow a low-cost evaluation, then shifting if necessary to a higher-cost translation and higher-cost evaluation. On the other hand, if one translates too much. producing full translations of document after document of relatively useless information. the rising costs concern not just the translator's fees but also the effort of whoever has to read through the translator's products to check that the information is useless. Wasteful translation costs can incur wasteful evaluation costs. Yet the relationship is not always so direct. Translators can put in a great deal of real effort (the classical "labour of the file") to produce a text that can be evaluated with relative ease. A lack of translative effort (as in ambiguous or highly redundant instruction manuals) can increase evaluation costs. And if high-effort "resistant" translations (as advocated by Venuti 1992) require high-effort evaluation processes, the link stands in no clear relationship to any mutual benefits except those accruing to the restricted readership of the Iranslation.

The analysis of simple cooperation suggests that translation costs should generally be kept as low as possible (although above zero), aiming to reduce the translation of unnecessary texts and trying to keep evaluation costs also as low as possible. The reason for this is simple. The higher the total transaction costs, the narrower the scope for agreement and the less happy social life will be.

\section{THE INTERESTS OF THE TRANSLATOR}

The above model does not see translators as negotiators. It portrays them as mediators who can enable or prohibit certain cooperation practices. If translators work with or for negotiators, their position is perhaps like that of Vance and Owen in the ruins of Yugoslavia. or the United Nations in Cambodia or Somalia. The hermeneutics that interest us concern not so much how the translator comes to terms with a text but how the actors on either side of the translator come to terms with each other. For the model, cooperation between these actors is more important than the priorities of the translator as mediator.

Cooperation could nevertheless be in the long-term interests of the translator as mediator. To put it too simply (the principle will soon be revised), the more the actors cooperate, the greater their mutual benefits and the more resources they can allocate to pay translators. This argument has several more virtuous aspects.

If $A$ has employed me to translate. it would seem logical for me to raise my rates to the highest level $A$ can afford and then advance A's cause as much as possible so I can be paid even more. Yet this unilateral frame would work against my long-term self-interest in two ways. First, each time I raise the translation costs, A's scope for bargaining will be reduced and $B$ s probabilistic information will have to be more exact. Transaction costs will thus be raised on both sides - the unilateral frame is delusive - and the scope for mutual benefits will be narrowed. There will be less cooperation and thus less demand for my translations. Second, more obviously, if I advance A's cause to the point where B is destroyed or robbed of any chance to participate in mutual benefits, cooperation will come to an end and there will be no further employment of translators in the interaction concerned. The translator's long-term interests are thus incompatible with unilateral allegiance.

This principle could inform actual decision-making operations. Situations inevitably arise where the translator must decide between the priorities of competing 
actors. No theory can prescribe the way translators should turn in all cases. However. especially on the large-scale level of translators as collectivities and actors as cultures, choices might ethically be made by privileging the interests of the weaker actor. In the years I spent translating into English for the president of Catalonia, my decisions were constantly in favor of promoting English-language awareness of Catalan culture (Pym 1991). This was not because I agreed with nationalist fanatics (I didn't and I don't). It was instead because the extreme imbalance between Catalan and English-language cultures meant that prolonged cooperation required special attention to the interests of the weaker side. After all, if Catalan culture became progressively weaker, its range of possible cooperation situations would diminish, the market for translations from Catalan would narrow, and there would he less demand for anyone's competence as a translator from Catalan. Translators" collective interests are thus generally best served by opting in favor of the weaker actor in any cooperation situation, regardless of whether this actor is the actual initiator, client, sender, or receiver.

Although this precept does no more than defend the collective interest of translators, it remains coherent with the ethical value of cooperation as such. It could moreover be incorporated into a wider cultural ecologism, arguing that cultural diversity is a value in itself and must be preserved. I nevertheless refrain from adopting this latter argument because I also recognize the need for cultures to change, 10 adapt themselves to new situations so as to develop better bargaining positions. An ethics of translation is not required to defend the eternal values of Bosnian Muslims, Tibetan monks. French farmers, or Scottish poets. Cultural rigidity or failure to adapt is a pity. but it is a failure.

A further consequence of the transaction-cost model is that. allowing that their own interests are generally compatible with the ethical value of cooperation, translators should be prepared to do rather more than just translate. If they are in a position to carry out other mediatory tasks, they should do so. This could involve things like actively preselecting information, advising on how a particular text should be translated, and suggesting how best to act in order to attain cooperation. A final consequence is of course that translators should be trained to carry out this wider range of mediatory tasks. More pointedly. they should be trained to know when not to translate.

\section{TRANSLATION AND LANGUAGE LEARNING;}

Translation is just one of several strategies for intercultural communication. The main alternative strategy is probably language learning. which does away with the need for translation by having one actor speak the language of the other or by having both adopt a lingua franca. Since language learning requires very high initial effort and costs, it is a bad strategy for one-off or short-lerm cooperation. However. once a language has been learnt to any degree of proticiency, the repeat costs become minimal and will reduce with continued use. Language learning is thus a good strategy for long-term cooperation. Translation costs, on the other hand, decline minimally. Some reduction in social effort does come about with repeated translating of the same subject matter. especially once basic terminology has been established and the translator gains familiarity with the actors. But there is no drastic drop; translators are still paid at fairly constant rates, hy the hour or page. All else being equal (which is never the case), the costs of the two strategies over time might be represented in the following way: 


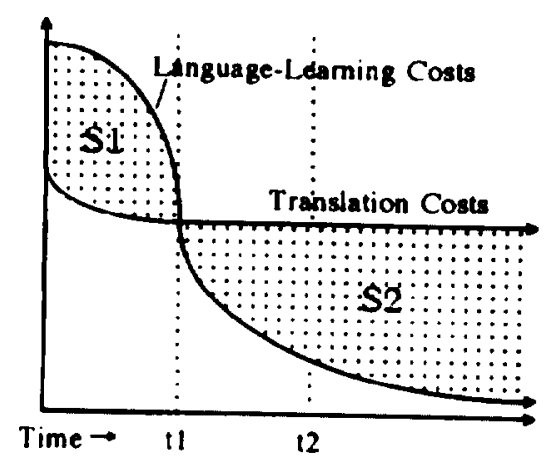

Area SI quantifies the relative savings to be gained from a translation strategy in short-term situations. Area S2 shows the savings from language learning in long-term situations. If the duration of the cooperation situation is less than $t 1$, translation should be used. If it is between $\mathrm{tl}$ and 12 (the point in time where $\mathrm{Sl}=\mathrm{S} 2$ ), translation should be mixed with language learning, ideally in the proportion of S1 to S2. For anything longer than 12 , of course, language-learning strategies should become progressively dominant.

Assuming that high transaction costs are generally to be reduced, actors should select their strategy according to the probable duration of the cooperation situation, which should be seen as including whatever communication is needed to ensure continued cooperation. Translation is clearly better for an initial contact meeting or a one-off conference. The Barcelona Olympic Games, as a four-year project, justified translation strategies yet was near the threshold where language learning was sometimes more economical, warranting intensive language classes for the main organizers (Pym 1993). The European Union, if one believes it to be a long-term project, should rationally adopt language-leaming strategies (as does EFTA, for which the negotiating language is English). Indeed, the fact that translation still remains important within EU institutions contributes to significant and unsustainable transaction costs. Coulmas estimates that the EU's language policy consumes some $40 \%$ of the total administrative budget. The reason, says Coulmas, is a form of linguistic nationalism that has little to do with the interests of long-term cooperation, since the Union "has heen used by member states to defend their languages" privileged position rather than being given the chance to produce a language policy of its own" (1990: 8). The politics of symbolic value have so far won out over the analysis of transaction costs.

One possible solution to this problem is to invest in advanced computer-assisted translation, which could make the above translation-cost curve look like the languagelearning one (high initial costs for very low repeat costs). Yet the difficulty of this solution. beyond the cost of developing the technology, is the potential increase in evaluation costs. which would then have to be reduced by some other means. Who is going to read all the automatically produced translations?

A more immediate sign of a change is the adoption of a "real-needs" policy, combining translation with the language-leaming strategies needed for multilingual conversations. But the current enlargement of the EU should require an even more significant move away from translation. The professional translators we are now training will eventually have to turn to a wider range of no less complicated mediatory tasks.

There is an interesting contradiction here. We have assumed that translators' collective interests are broadly compatible with long-term cooperation. Yet we now find that some long-term relationships are better suited to language-learning strategies. Ethically, 
translators should recognize this. In such situations they should recommend against translation, even when this goes against their collective interest as translators. Some years ago I translated physics and biology from Spanish into English, earning good money and learning many interesting things. But since Spanish science is in an inextricably longterm relationship with English-language science, my strategy changed. Once I realized that most of the Spanish authors could write at least poor English, it became quicker for me and cheaper for them to adopt a language-learning stralegy. I sat down with them and corrected their papers, fixing my fees at language-class rates. The authors learnt better English; I continued to learn interesting things for a while; and translation gave way to a more rational long-term transaction strategy.

\section{THE. TRANSACTION-COST MODEL, WITHIN TRANSI.ATION THEOKY}

The model I have presented is hased on the simplest level of cooperation. Its only properly ethical principles are non-destruction of the other and the priority of long-term cooperation. I have not insisted that actors be prepared to make substantial short-term sacrifices for the sake of long-term cooperative relationships, although one does find cases of this happening (Dutch and Erse are not official EU languages; Spaniards have effectively sacrificed Spanish as a language for the initial announcing of scientific advances). In terms of international relations theory my model remains optimistically liberal rather than pessimistically restrictive or realist (cf. Krasner 1983: 1-8: Kohler-Koch 1989: 17-19).

The transaction-cost model has been drawn from a neoclassical view of decisionmaking, a view that has correctly been criticized in recent translation theory (Séguinot 1991: Tirkkonen-Condit 1992). Yet the consequences of the model need not be restricted to neoclassical assumptions or an ethics of crude economic efficiency. The model does not say everyone is a rational egoist: it merely shows that cooperation can exist in the case of rational egoists. If the rationalist conditions on subjectivity are then relaxed, allowing for irrational or non-egoistic generosity or stupidity, the chances of cooperation in fact become greater ( $f$. Keohane 1984: 112ff). The model can thus be taken beyond its initial assumptions. Indeed, by the time one gets to 1 wo actors making uncertain assumptions about the other's status and future actions, there is no reason why its intersubjectivity could not become rather Lacanian.

The model's prime purpose is clearly not to describe everything that happens or could happen in the field of translation. It merely describes something that can happen cooperation - and some of the ways in which translation can contribute to this outcome. The model becomes ethical when one argues that cooperation should happen wherever possible. This is not moralizing in a narrow prescriptive sense. The model offers no more than a simple guide for the perplexed, proposing a course of action for the attainment of a general goal. If a translator sees no ethical value in that goal - if hegemonic relations or nationalist priorities are thought to be better than cooperation -, then the model has nothing to propose to that particular translator.

The model might nevertheless be of interest to translation theory to the extent that it introduces a frame for debates about ethics. Beyond delimiting the translator s responsibility, it can attribute a goal to translation itself. It can moreover inscribe this goal within a wider social ethics, the ultimate goal of which, in Aristotelian terms, is the attainment of happiness. I see no reason why translation theory should not talk aboul a litle happiness.

Let me close by briefly suggesting how the transaction-cost model might be related to a few existing translation theories. 
Game theory was of course introduced into translation theory by Levy (1967), whose general "minimax" principle - that the translator must exert minimum effor for maximum effect - remains valid. But Levy never defined the general "effect" of translation, allowing his essay 10 wander between source-text determinism and reader-response relativism. The above model can give a general criterion for the weighting of such variants. Further, whereas Levy adopted a restrictive view of translation as a "game with complete information" (1967: 39), the transaction-cost model assumes no such closure, accepting probabilistic behavior in a world of uncertainties. In fact, the model suggests that the minimax principle would be contradicted by any insistence on complete information or absolute certainty. Some factors should remain relatively unknown precisely because the cost of reducing their uncertainty will exceed the potential mutual benefits. Interestingly enough. Christiane Nord's model of translation accepts Levy's determinist principle (1988: 40) and consequently recommends that translators invest quite extreme effort in source-text analysis. The principle of complete information might be a useful fiction in translator training, but it unthinkingly sanctions transaction costs that are often far higher than an ethics of cooperation can allow.

Related doubts about the transaction-cost model might come from theorists concerned with the translating of literary or philosophical texts. Following Schleiermacher's exclusion of negotiation from the realm of translation proper (1813), some might argue that literary-philosophical translation concerns disinterested aesthetic value or operates on a diachronic relation between texts rather than a synchronic relation between people. Some might even argue that. because of diachrony, most literary-philosophical actors do not live in the same street, making translation a fact of one actor only. Several answers are possible here. First, if one were to ascribe an infinite value to aesthetic appreciation or philosophical enlightenment as a mutual henefit to be attained between author and reader, then the logic of Pascal's wager could wholly justify infinite translation costs. The transaction-cost model would be able to describe a certain literary-philosophical ideology, if not entirely the actual practice of literary-philosophical translation. Second, wherever values are less than infinite, a sociologist might insist that any society engaged in the reception and translation of great foreign texts has more than aesthetic interests at stake. Translations from dead cultures tend to enter conflicts within the target society, making cooperation an internal rather than transcultural ideal. Further, literary-philosophical translations between co-existing cultures provide a thousand intangible pieces of information on the mind sets of major trading partners, potential political enemies, or the controllers of international power relations. Transcultural literary formations, Goethian Weltliteratur if you like, provide invaluable common references for the social elites forging the most crucial international cooperation relationships. There are many quite nonaesthetic or non-philosophical reasons why a society might invest part of its resources in the translation of great foreign texts. Without falling back on any economic determinism, these reasons can be described by a notion of cooperation adapted to macrosocial levels.

Beyond the specificity of great texts, the transaction-cost model fits in with dialogic theory as it has influenced thought on translation at least since Schleiermacher and more recently with reference to relevance theory (Gutt 1991) and Bakhtin (Lang 1992). Yet the model retains certain peculiarities. It does not assume actors that are axiomatically separate, equal, or defined by unchangeable specificities or intentions. Although distinguished by otherness, both sides are from the outset conditioned by the state and potential of their interrelationships. Theirs is a mutually active otherness. There is no question of having to decide between source and target priorities as such. Nor does the model mean the actors are dominated by systems or polysystems within any larger system. Cooperation situa- 
tions only concern those areas in which mutual benefits can be attained: they do not automatically concern relationships between entire systems.

Recent applications of postcolonial theory to translation (as in Bassnett 1991: Niranjana 1992) might benefit from the transaction-cost model to the extent that it refuses any systemic read-off from power relationships. Even when $\mathrm{A}$ and $\mathrm{B}$ are highly unequal they can still cooperate rationally and overcome imbalances in certain areas, independently of any prolonged ideological struggle. This is why negotiation theory talks about "regimes" as the sets of principles and norms required to achieve cooperation, explicitly to distinguish such principles and norms from totalizing theories of "international systems" like colonialism (Keohane 1984: 25-28, 57-59). Hegemony, conflict, and exploitation to not infiltrate everything. Nor do they provide good guidelines for future action in the field of translation.

The transaction-cost model should also be compatible with the broad principles of Holz-Mänttäri's Handlungstheorie (1984) and Vermeer's Skopostheorie (as in Reiss \& Vermeer 1984). However, if the less careful target-oriented approaches occasionally imply a mercenary ethics based on short-term unilateral rewards (do what your client tells you to do; shoot where you're told to shoot). acceptance of mutual benefits as the general goal of translation might give our work a more noble and perhaps happier purpose.

\footnotetext{
Notes

* This research was carried out with the assistance of a fellowship from the Alexander von Humboldi Foundation for work at the Special Research Center in Literary Translation (Sonderforschungstereich 3(19) at the University of Göttingen. Germany.
}

\section{REFERENCES}

BASSNETT. Susan (1991): "Translation and Ideology", Koind. 1:2, pp. 7-32

COULMAS. Florian (1991): "European Integration and the Idea of a National Language". Florian Coulmas (Ed.). A Language Policy for the European Communiry. Prosperts and Quandaries. Berlin. New York. Mouton de Gruyter, pp. 1-37.

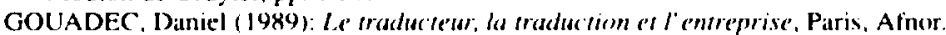

GUTT, Emst-August (1991): Translation and Relesance. Cognition and Contex, Oxford, Basil Blackwell.

HOLZ-MÄNTTÄRI, Justa (1984): Translatorisches Handeln. Theorie und Methode. Helsinki, Academia Scientiarum Fennica.

KEOHANE, Robert O. (1984): Afier Hegemen!: Cooperation and Discord in the World Poltrical Economy, Princeton NJ, Princeton University Press.

KOHLER-KOCH, Beate (1989): "Zur Empirie und Theorie internationaler Regime". Beate Kohler-Koch (Ed.), Regime in den imternationalen Beziehungen. Baden-Baden. Nomos.

KRASNER. Stephen D. (198.3): "Structural Causes and Regime Consequences: Regimes as Intervening Variables". Stephen D. Krasner (Ed.). International Regimes, Ithaca \& London. Cornell University Press. Fifth Printing. 1989

LANG. George (1992): "La Belle Altérite: Towards a Dialogical Paradigm in Translation Theory?". Canadian Revien of Comparative Literufure. 19:1-2, pp. 237-251.

LEVY, Jirí (1967): "Translation as a Decision Process". Andrew Chesterman (Ed.). Readings in Trans/ation Theory, Helsinki, Oy Finn Lectura Ab, 1989, pp. 37-52.

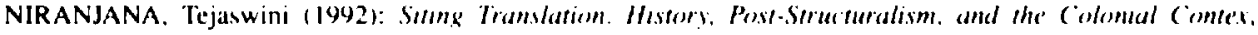
Berkeley \& Oxford, University of (alifornu Press.

NORD. Christiane (I988): Teuanalyse und Öhorse'ze'n, Heidelberg. Julius Groms.

NORTHROP. Filmer Stuan Cuckow (1952): The Taming of the Nations. A Sndy of the ('ulural Bases of International Policy. Reprint. Wextbridge (onnecticul. ()x Bow Press, 1987.

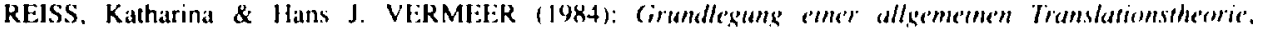
Tübingen. Niemeyer.

SCHLEIERMACHER, Friedrich (181.3): "liher die verschiedenen Methoden des íberset/ens", Sïmuliche" Werke. Drille Aberilung Zur Philosisphic. Vol. 2., Berlin, Reimer, 1838, pp. 207-245.

PYM. Anthony ( $\mid(x) 11$ : "Translational Ethics and the Recognition of Stateless Nations". Fremdsprachen. I $90 \mid: 4$, pp. $31-35$. 
PYM, Anthony (1993): "Translating the Symbolic Olympics at Barcelona", Paper presented to the XIX International FILLM Congress, Brasilia, August 1993. Publication in the comesponding proceedings.

SÉGUINƠT, Candace (1991): "A Study of Student Translation Strategies". Sonja Tirkkonen-Condit (Ed.). Empirical Research in Translation and Interrultural Studie. Tubingen. Gunter Narr, pp. 79-88.

TIRKKONEN-CONDIT, Sonja (1992): "A Theoretical Account of Translation - Without Translation Theory?". Target. 4:2, pp. 237-245.

VENUTI. Lawrence (1992): "Introduction", Lawrence Venuti (Ed.), Rethinking Translation. Discourse, Subjectivity. Ideolsgy. London \& New York. Routledge. 